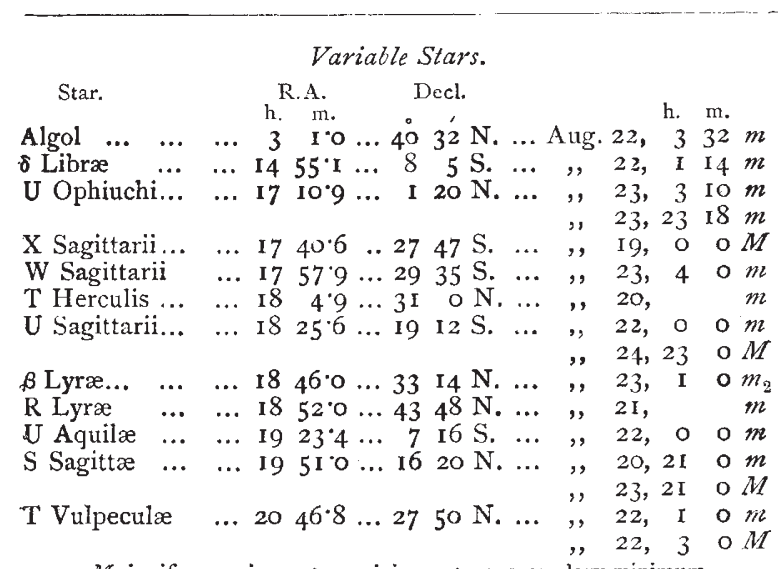

$M$ signifies maximum ; $m$ minimum ; $m_{2}$ secondary minimum.

\section{Meteor Showers.}

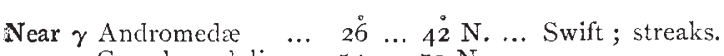

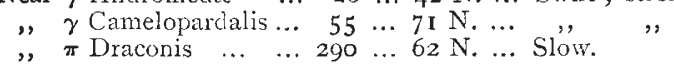

\section{THE CONGRESS OF GERMAN NATURALISTS $A N D$ PHYSICIANS.}

THE sixty-second Congress of German Naturalists and Physicians will be held, as we have already announced, at Heidelberg, from September I 8 to 23 ; and the meeting promises to be one of great interest. Dr. G. Quincke and I)r. W. Kiihne, by whom the various necessary arrangements are being made, have issued a programme, and take the opportunity to say that all naturalists, physicians, and students of the natural sciences, who may choose to attend the meeting, will be cordially welcomed. Although by its statutes the Congress consist3 only of Germans, foreign investigators, by being present and taking part in the proceedings, give much pleasure to their German colleagues.

The three general meetings will be held in the great hall of the Heidelberg Museum on September 18,20 , and 23. To the second of these general meetings, on september 20 , a scheme embodying new statutes will be submitted for cunsideration. This scheme has been worked out by a committee in consequence of resolutions passed at the Congress held last year at Cologne.

According to the old statutes of 1822 , still in force, the Congress consists of members and associates, but only the former have the right of voting. Everyone who has written a book on natural science or on medicine is regarded as a member. No one, how ever, who has merely written an inaugural dissertation can be considered as an author. Admission as associates is open to all who have occupied themselves scientifically with natural science and medicine. The ordinary ticket costs 12 marks; and the same ticket may be obtained for ladies at half the price. In return for an annual subscription of 5 marks, paid in accordance with the decisions of the Cologne Congress last year, the members receive a special member's ticket. The ticnets will often have to be shown, so that members and associates ought to have them always ready.

Resolutions can be passed only at a general sitting ; and every thing is decided by the votes of a majority of the members. Resolutions with regard to scientific theses are not adopted either at the general sittings or in the Sections. The Sections elect their own Presidents, and may, in addition to the Secretary previously appointed, nominate, if necessary, a second or a third Secretary.

In connection with the meeting, there will be an exhibition of scientific apparatus, instruments, and preparations. It will be held in the town gymnastic hall (Ttwrquhalle), Grabengasse, 22. Arrangements are being made for this exhibition by a special committee, the president of which is Herr Stadtrath Leimbach, 59 Gaisbergstrasse, Heidelberg, to whom all communications relating to the exhibition should be addressed. The ordinary ticket secures admission to the exhibition, which will be open daily, to members and associates only, from 8 to I I o'clock a.m. During these hours, explanations will, if desired, be given by exhibitors or their representatives. After 11 o'clock the exhibition will be of en to the public, who will have to pay for admission. A catalogue will be provided for members and associates.

The Directors of the Museum and of the Harmonic Society have placed their rooms at the disposal of the Congress; and through the kindness of the civic authorities, and of the Society to which the Museum belongs, it has been arrangel that a concert shall be given in the town garden on September 18 , and a festival in the Castle grounds on September 20; that the Castle shall be illuminated on the evening of September 23 ; and that a ball shall be given in the Museum on September 21. Tickets for the dinner in the great hall of the Museum, on September I9, will be issued at the Reception Room on Tuesday and Wednesday, September 17 and 18 . The Reception Room and Inquiry Office will be on the ground floor of the Bayrischer Hof, 2 Rohrbacher Strasse, near the railway station.

Applicat:ons for lodgings will be received by Herr Rathschreiber Webel (Rathhaus, Heidelberg), Secretary of the Lodgings Committee. A representative of this Committee will be present in the Recention Room.

A daily Bulletin will be issued during the sitting of the Congress. Every morning it will be found in the Reception Room, with a list of members and associates; also with the orders of the day in the Sections, \&c. Reports of papers can only be printed afterwards in the scientific part of the Bulletin. Papers which are intended for publication must be written plainly, and handed in not later than October 8.

A post and telegraph office will be open in the ground hoor of the University from 8 a.m. to $8 \mathrm{p}$. m., and a room will be set apart for the writing of lelters. Dr. Quincke and Dr. Kuihne have not been able to induce the railway companies to issue tickets at a reduced price.

On Sunday, September 22, the following excursions will be made :-

(I) Through the Valley of the Neckar to Neckarsteinach, Hirschhorn, Eberlach, Einstthal.

(2) By the Bergstrasse to Weinheim, Bensheim, Auerbach, Zwingenberg, Jugenheim.

(3) In the ralatinate, to Speyer, Neustadt, Annweiler, Diirkheim.

(4) To Mannheim, for the examination of the collections there, and for a visit to the opera.

All members and associates (even those who may already have their tickets) are requested to write their names on the list in the Reception Room, and at the same time to give their cards, with name, titles, and place of residence.

The following is the general order of the day:-

Tuesday, September 1 7 : 9 a.m., opening of the Exhibition; 8 p.m., friendly meeting in the Museum.

Wednesday, the 18 th $: 9$ a.m., first general meeting in the great hall of the Museum. (I) Opening of the Congress: Speeches. (2) Lecture by Geh. Rath von Meyer (GöttingenHeidelberg), on "Chemical Problems of the Present Day." (3) Lecture by Dr. G. H. Otto Volger (Frankfort), on the "Life and Achievements of Dr. K. Schimper."

Midday: Assembling and formation of the Sections.

Afternoon: Sittings of the Sections.

7 p.m. : Concert in the Town Garden.

Thursday, the I 9 th : Sittings of the Sections ; 5 p.m, dinner in the great hall of the Museum.

Friday, the zoth : 9 a.m., second general meeting in the great hall of the Museum. (I) Lecture by Prof. Hertz (Bonn), on "The Relations between Light and Electricity." (2) Consideration of the scheme of new statutes, under the presidency of Dr. Virchow, as Chairman of the Committee by which the scheme was drawn up. (3) Election (a) of the new Committee, (b) of the next place of meeting, (c) of the business managers of the next meeting.

Afternoon: Sittings of the Sections.

6.30 p.m. : Festival at the Castle.

Saturday, the $2 \mathrm{rst}$ : Sittings of the Sections. $7 \cdot 30$ p.m., ball in the Museum.

Sunday, the 22nd: Excursions in the neighbourhood.

Monday, the $23 \mathrm{rd}: 9 \mathrm{a} . \mathrm{m}$, third general meeting in the great hall of the Museum. (I) Lecture by Prof. Th. Puschmann (Vienna), on "The Significance of History for Medicine and the Natural Sciences." (2) Lecture by Prof. Brieger (Berlin), on "Bacteria."

Afternoon: Sittings of the Sections.

7.30 p.m. : Illumination of the Casile. 
We append a list of the Sections:-(I) Mathematics and Astronomy ; (2) Physics ; (3) Chemistry ; (4) Botany ; (5) Zoology ; (6) Entomology ; (7) Mineralogy and Geology ; (8) Ethnology and Antbropology ; (9) Anatomy ; (ro) Physiology; (II) General Pathology and Pathological Anatomy ; (I2) Pharmacology ; (I3) Pharmacy and Pharmacognosis ; (I4) Medicine; (I5) Surgery ; (I6) Gynæcology; (I 7) Children's Diseases ; (I8) Neturology and Pyschiatry; (19) Diseases of the Eye; (20) Diseases of the Ear; (2I) Laryngology and Rhinology; (22) Dermatology and Syphilis ; (23) Hygiene ; (24) Medical Jurisprudence; (25) Medical Geography ; (26) Military Sanitation ; (27) Dentistry; (28) Veterinary Medicine ; (29) Agricultural Chemistry; (30) Mathomatics and the Natural Sciences in Relation to Education; (3I) Geography; (32) Philosophical Instruments.

THE PROGRESS OF SCIENCE AS EXEMPLIFIED IN THE ART OF WEIGHJNG AND MEASURING. ${ }^{1}$

T'WO centuries ago the world was just beginning to awaken from an intellectual lethargy which had lasted a thousand years. During all that time the children had lived as their parents before them, the mechanical arts had been at a standstill, and the dicta of Aristotie had been the highest authority in science. But now the night of medirvalism was approaching its end, and the dawn of modern progress was at hand. Galileo had laid the foundation for accurate clocks by discovering the isochronism of the simple pendulum; had proved that under the action of gravity light bodies fall as rapidly as heavy ones; had invented the telescope, and with it discovered the spots on the sun, the mountains on the moon, the satellites of Jupiter, and the so-called triple character of Saturn; and, after rendering himself immortal by his advocacy of the Copernican system, had gone to his grave aged, blind, and full of sorrows. His contemporary, Kepler, had discovered the laws which, while history endures, will associate his name with the theory of planetary motion, and he also had passed away. The first Cassini was still a young man, his son was a little child, and his grandson and great-grandson, all of whom were destined to be directors of the Paris Observatory, were yet unborn. The illustrious Huyghens, the discoverer of Saturn's rings and the father of the undulatory theory of light, was in the zenith of his powers. 'The ingenious Hooke was a little younger; and Newton, towering above them all, had recently invented fluxions, and on April 28, I686, had presented his "Principia" to the Royal Society of London, and given the theory of gravitation to the world. Bradley, who discovered nutation and the aberration of light; Franklin, the statesman and philosopher, who first drew the lightning from the clouds; Dollond, the inventor of the achromatic telescope; Euler, the mathematician who was destined to accomplish so much in perfecting algebra, the calculus, and the lunar theory ; Laplace, the author of the "Mécanique Céleste" Rumford, who laid the foundation of the mechanical theory of heat; Dalton, the author of the atomic theory, upon which all chemistry rests ; and Bessel, the greatest of modern astronomers - these and others almost as illustrious, whom we cannot even name to night, were still in the womb of time.

Pure science first felt the effects of the new intellectual life, and it was more than a century later before the arts yielded to its influence. Then came Hargreaves, the inventor of the spinning-jenny; Arkwright, the inventor of the cotton-spinning frame; Watt, who gave us the condensing steam-engine; Jacquard, the inventor of the loom for weaving figured stuffs; Murdock, the originator of gas lighting ; Evans, the inventor of the high-pressure steam-engine; Fulton, the father of steam navigation; Trevithick, who ranks very near Watt and Evans in perfecting the steam-engine; and Stephenson, the father of railroads. If now we add the names of those who have given us the telegraph, to wit: Gauss, the eminent physicist and the greatest mathematician of the present century ; Weber, Wheatstone, and Henry-all famous physicists--and Moree, the inventor and ergineer; we have before us the demi-gods who have transformed the ancient into the modern world, given us machinery which has multiplied the productive power of the human race many-fold, annihilated time and space, and bestowed

I Annual Address of Dr. William Harkness, President of the Ph 'osophical Society of Washington, delivered on December 10, 1887 . upon toiling millions a degree of comfort and luxury which was unknown to kings and emperors of old.

The discoveries and inventions of the last two centuries have so far exceeded all others within historic times that we are amply justified in calling this an age of phenomenal progress, and under the circumstances a little self-glorification is pardonableperhaps even natural. The weekly and monthly records of scientific events which appear in so many newspapers and magazines are the immediate result of this, and the great increase of ephemeral scientific literature has led multitudes of educated people to believe that such records represent actual progress. The multiplication of bricks facilitates the building of houses, but does not necessarily improve architecture. Similarly, the multiplication of minor investigations improves our knowledge of details, but rarely affects the great philosophic theories upon which science is founded. The importance of human actions is measured by the degree in which they affect human thought, and the only way of permanently affecting scientific thought is by modifying or extending scientific theories. The men who do that are neither numerous nor do they require weekly paragraphs to record their deeds; but their names are honoured by posterity. Even in this golden age the advance of science is not steady, but is made by spasmodic leaps and bounds. Mere scientific brick-making, commonly called progress, is always the order of the day until some genius startles the world by a discovery affecting accepted theories. Then every effort is directed in the new line of thought until it is measurably worked out, and after that brick-making again resumes its place. While the progress in two centuries has been immense, the progress in a week or a month is usually almost nil. Optimism has its uses in many departments of human affairs, but science should be cool and dispassionate, having regard only for the truth. To make a trustworthy estimate of the actual state of the whole vast realm of science would be a task beyond the powers of any one man; but perhaps it will not be amiss to spend the time at our disposal this evening in briefly reviewing the recent progress and present condition of the fundamental processes upon which the exact sciences rest -I allude to the methods of weighing and measuring.

Physical science deals with many quantities, but they are all so related to each other that almost every one of them can be expressed in terms of three fundamental units. As several systems of such units are possible, it is important to select the most convenient, and the considerations which guide us in that respect are the following :-

(r) The quantities selected should admit of very accurate comparison with other quantities of the same kind.

(2) Such comparisons should be possible at all times, and in all places.

(3) The processes necessary for making such comparisons should be easy and direct.

(4) The fundamental units should be such as to admit of easy definitions and simple dimensions for the various derived units.

Scientific men have long agreed that these requirements are best fulfilled by adopting as the fundamental units a definite length, a definite mass, and a definite interval of time. Length is an element which can be very accurately measured and copied, but it must be defined by reference to some concrete material standard, as, for example, a bar of metal ; and as all substances expand and contract with changes of temperature, it is necessary to state the temperature at which the standard is correct. A standard of mass, consisting of a piece of platinum, quartz, or other material not easily affected by atmospheric influences, probably fulfils the conditions set forth above better than any other kind of magnitude. Its comparison with other bodies of approximately equal mass is effected by weighing, and as that is among the most exact of all laboratory operations, very accurate copies of the standard can be made, and they can be carried from place to place with little risk of injury. Time is also an element which can be measured with extreme precision. The immediate instruments of measurement are clocks and chronometers, but their running is checked by astronomical observations, and the ultimate standard is the rotation of the earth itself.

It is important to note that the use of three fundamental units i s simply a matter of convenience and not a theoretical necessity, for the unit of mass might be defined as that which at unit distance would generate in a material point unit velocity in unit time; and thus we should have a perfectly general system of measurement based upon only two fundamental units-namely 